\title{
Fingertip Necrosis due to Chemical Burn from Glacial Acetic Acid: A Case Report
}

\author{
Cheon Ho Song (), Jung Hyun Park (D), Dong Chul Lee (D), Jin Soo Kim (D), Sung Hoon Koh (D), Si Young Roh (D), \\ Kyung Jin Lee (iD) \\ Department of Plastic and Reconstructive Surgery, Gwangmyeong Sungae General Hospital, Gwangmyeong, Korea
}

\begin{abstract}
Glacial acetic acid is a high-purity acetic acid that is mainly used as a solvent in chemical production and for various purposes in the food and pharmaceutical industries. It is safe enough to be used for chemical peeling when diluted, and has been used in folk remedies for warts, athlete's foot, and eczema. Indeed, such conditions are the most common reason for exposure to glacial acetic acid. In the present report, we describe the case of a 10-year-old girl who presented with pain and necrosis of the distal phalanx of her left index finger. Two days prior, her fingers had been wrapped overnight with a paste of flour mixed with glacial acetic acid to treat warts. We irrigated the affected area with normal saline, applied a mupirocin ointment, and administered prostaglandin E1. However, the necrosis progressed rapidly. After 10 days, the girl's fingertip was amputated, and a hypothenar free flap was performed. The case represents a severe chemical burn resulting from the misuse of glacial acetic acid, requiring surgical treatment.
\end{abstract}

Keywords: Acetic acid; Burn, chemical; Finger injury; Necrosis; Reconstructive surgical procedure

\section{Introduction}

Acetic acid, the major component of vinegar, is a colorless, hygroscopic, and weak acid. In its anhydrous form with $99.5 \%$ to $100 \%$ purity, it is known as glacial acetic acid because it has a freezing point of $16.6^{\circ} \mathrm{C}$, which is only slightly below room temperature; the word "glacial" refers to the ice-like crystals that form under its freezing point [1]. As acetic acid is safe enough to be used in food when diluted to approximately $5 \%$, sufficiently diluted acetic acid has also been used for chemical peeling. Moreover, glacial acetic acid is used in folk remedies to treat warts, athlete's foot, and eczema, though it can cause contact dermatitis or chemical burns upon contact with the skin $[2,3]$. Glacial acetic acid is easily available for anyone to purchase online and offline. In the present report, we describe the case of a 10-year-old girl with chemical burns caused by prolonged exposure to undiluted glacial acetic acid. Her injury resulted in necrosis of the fingertip and required surgical treatment. This study was performed in accordance with the principles of the Declaration of Helsinki. Written consent was obtained from the patient and her mother for the use of wound photographs.

\section{Case}

A 10-year-old girl visited our clinic with multiple chemical burns on both hands combined with decreased blood flow in the left index finger. A day prior, to remove warts on the girl's thumb, index, middle, and ring fingers, her mother had wrapped her fin-

\section{Case Report}

Received: September 6, 2021

Revised: October 6, 2021

Accepted: October 7, 2021

Corresponding author:

Dong Chul Lee, M.D.

Department of Plastic and Reconstructive Surgery, Gwangmyeong Sungae General Hospital, 36 Digital-ro, Gwangmyeong 14241, Korea

Tel: +82-2-2680-7637

Fax: +82-2-2615-7218

E-mail: ophand@gmail.com

This is an Open Access article distributed under the terms of the Creative Commons Attribution Non-Commercia License (https://creativecommons.org/licenses/by-nc/4.0/) which permits unrestricted non-commercial use, distribution, and reproduction in any medium, provided the original work is properly cited.

C) 2021 Korean Wound Management Society 
gers with a paste made from undiluted glacial acetic acid and flour-a common folk remedy. The next morning, she experienced excruciating pain in the wrapped fingers. Bullous lesions were observed where the paste had been applied. She was immediately admitted to a local university hospital. The injured fingers were irrigated using normal saline and then dressed with wet gauze. Discoloration in her left index fingertip was observed, whereon professional treatment was recommended. In the evening, the patient was transferred to our hospital. At the time of admission to our clinic, blisters had formed around multiple warts on both hands (Fig. 1A and B). There was no blood flow in the distal phalanx of the left index finger. After admission, we continuously irrigated the lesions with normal saline. We also applied a mupirocin ointment (20 $\mathrm{mg} / \mathrm{g}$ ) and foam dressing, and administered an intravenous injection of $5 \mu \mathrm{g}$ prostaglandin E1 (Alostin; Dongkook Pharm., Seoul, Korea) dissolved in $500 \mathrm{~mL}$ of normal saline once a day for the first 6 days. Considering the patient's weight of $30 \mathrm{~kg}$, half the daily adult dose of $10 \mu \mathrm{g} /$ day was administered. Despite the treatment, the necrosis continued to progress rapidly for 1 week without improvement (Fig. 1C and D). Necrosis was confirmed, and an amputation with reconstructive surgery was performed on the 10th day (Fig. 2). The entire distal phalanx bone was amputated, with the amputated segment measuring $2.2 \mathrm{~cm}$ in length (28.6\% of the finger). The skin and soft tissues of the amputated stump were debrided as far as the first third of the middle phalanx. They were then reconstructed using an ipsilateral hypothenar free flap to cover the exposed bone and maintain the length of the finger. Three weeks after the injury, necrotic tissue was debrided from the right thumb, index, and middle fingers. After confirming that healthy granulation tissues had formed, split-thickness skin grafts were performed. Two months after surgery, the left index finger was shorter than normal, but the shape of the fingertip had been restored (Fig. 3A and B). We planned to replace the missing nails at a later date. Hypertrophic scars were observed at the skin graft sites (Fig. 3C).

\section{Discussion}

Glacial acetic acid is used in various fields, mainly as a solvent to produce chemicals, as well as in relatively small amounts in
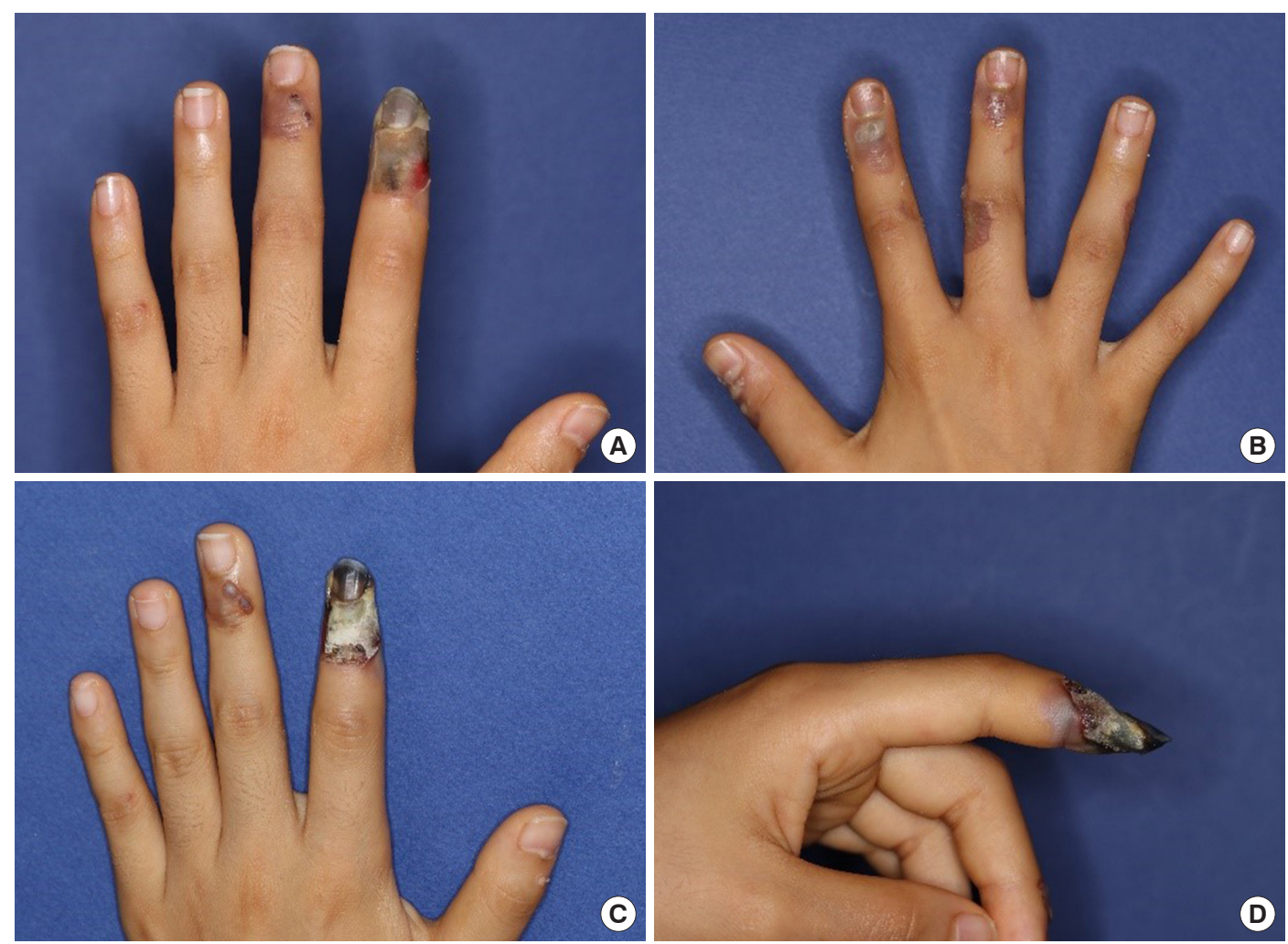

Fig. 1. Clinical presentation on the day of injury. (A, B) Blisters are observed around multiple warts on both hands, and the left index finger has no blood flow in the distal phalanx. (C, D) A week after the injury, necrosis of the fingertip has progressed in the left index finger. 

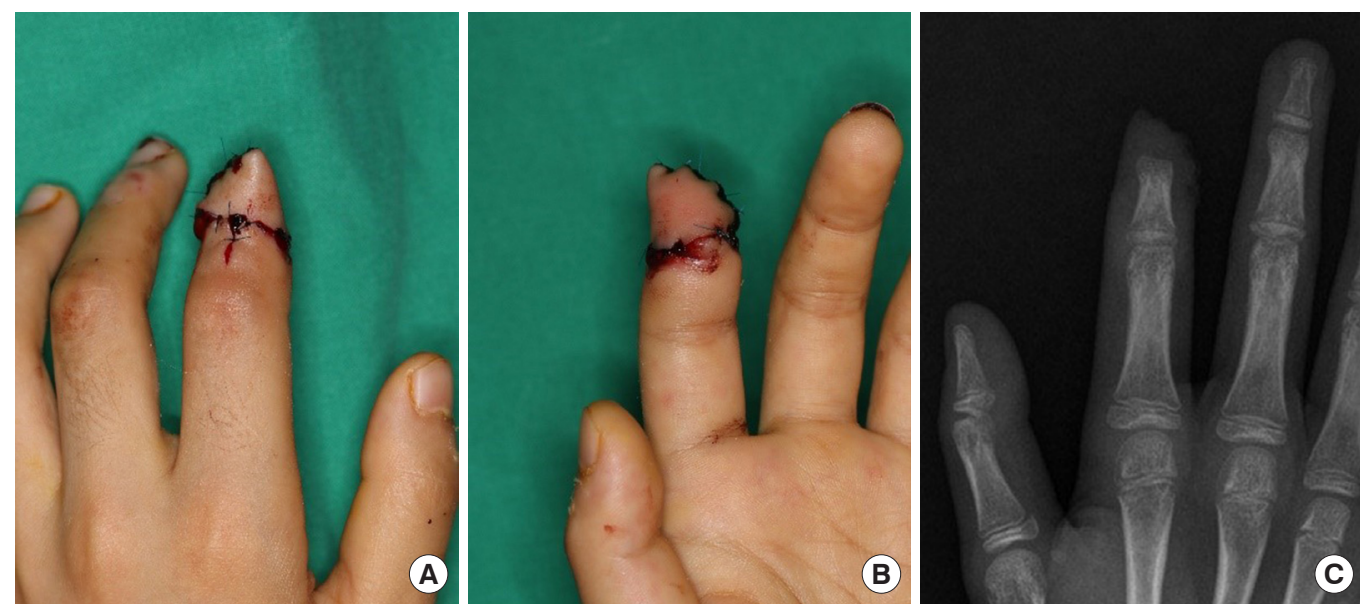

Fig. 2. Postoperative photographs and radiograph of reconstruction surgery. (A, B) The skin and soft tissues were amputated as far as the first third of the middle phalanx, and they were reconstructed using a hypothenar free flap. (C) The entire distal phalanx bone was amputated.
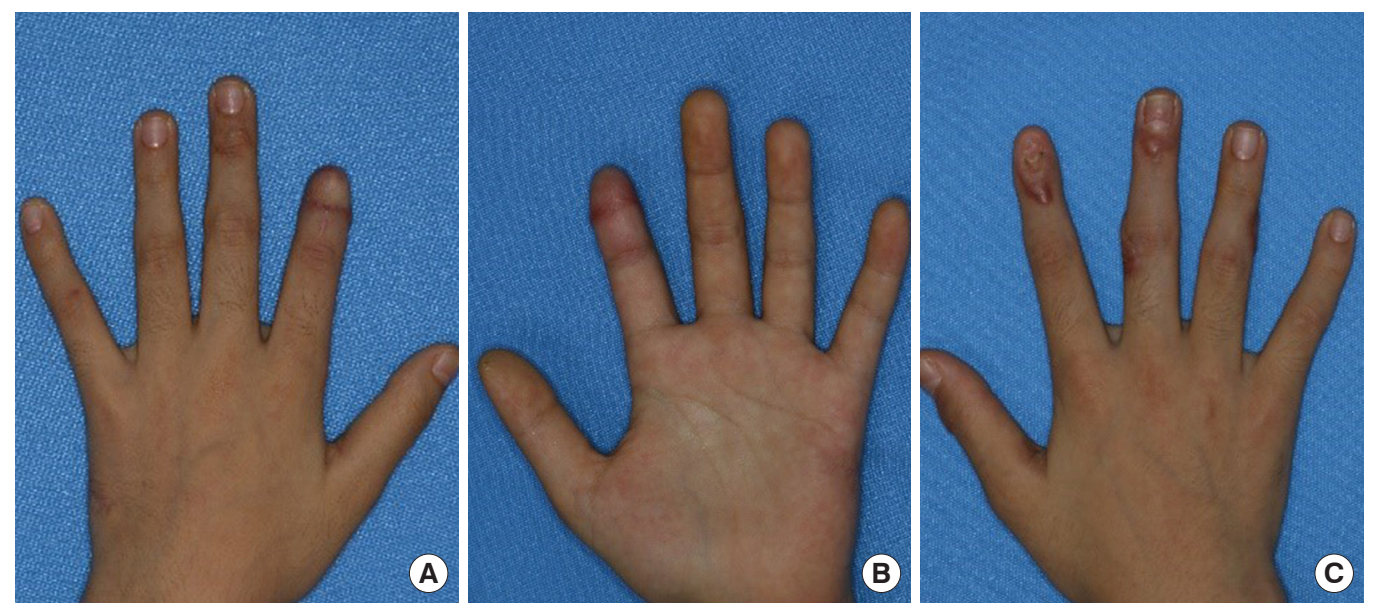

Fig. 3. Two months after the injury. (A, B) The left index finger is still shorter, but the shape of the fingertip has been restored. (C) Hypertrophic scars can be seen at the skin graft sites.

food [4]. When diluted to less than $5 \%$, acetic acid can be used to season food, as a topical treatment, and to treat external ear infections [5]. It is also used to screen for cervical cancer [6]. Glacial acetic acid is classified as a weak acid and is safe when diluted sufficiently. However, it acts as an irritant at concentrations of $10 \%-25 \%$; it is also corrosive at these concentrations and should be contacted with caution [4]. Exposure to undiluted glacial acetic acid can cause serious chemical burns, particularly if the exposure is prolonged.

Chemical burns account for the second most common burn-related hospitalizations after thermal burns [7]. Chemical burns have different mechanisms depending on whether they are caused by an acid or an alkali. Alkalis generally cause more tissue damage through liquefaction necrosis, which al- lows the chemical to diffuse deeper as tissue loosens; in contrast, acids cause coagulation necrosis due to consolidation of loose connective tissue, thrombosis of intramural blood vessels, ulceration, fibrosis, and hemolysis of red blood cells. Other factors affecting the severity of chemical burns include physical state, concentration, strength, and duration of contact with skin [7-9]. Acids commonly produce a dry eschar of varying colors from black to yellow, and treatment includes removal of any visible chemicals, as well as copious saline lavage. Tissue or skin grafting is recommended, with early resection of non-viable tissues [8].

Although few cases have been reported, glacial acetic acid is one of the most common causes of chemical burns [10]. One case of chemical burns was reported after an attempt to peel 
the face with a paste of flour mixed with undiluted glacial acetic acid instead of a professional procedure [2]. In another reported case, deep second-degree burns occurred when glacial acetic acid was applied and dried for 30 minutes to treat eczema on both hands [11]. Another case of burns occurred after a patient soaked both feet in undiluted glacial acetic acid for an hour to treat athlete's foot [11]. All these cases involved second-degree burns and were managed using conservative treatment. In severe cases, a split-thickness skin graft was performed $[2,10,11]$.

The present report describes the first case of amputation prompted by finger necrosis after glacial acetic acid chemical burns. The patient had suffered severe chemical burns that could not be managed using conservative treatment. As glacial acetic acid is registered as a food additive in South Korea, anyone can purchase it without restrictions and can be easily exposed. With the present case report, we aim to highlight the potential dangers of using glacial acetic acid to treat warts, athlete's foot, or eczema.

\section{Conflict of interest}

No potential conflict of interest relevant to this article was reported.

\section{ORCID iDs}

\section{Cheon Ho Song}

Jung Hyun Park

Dong Chul Lee

Jin Soo Kim

Sung Hoon Koh

Si Young Roh https://orcid.org/0000-0001-7096-2836

https://orcid.org/0000-0001-6403-5438

https://orcid.org/0000-0003-4211-6901

https://orcid.org/0000-0003-3369-2974

https://orcid.org/0000-0002-8094-2561

https://orcid.org/0000-0002-8625-6124
Kyung Jin Lee

https://orcid.org/0000-0002-9448-8291

\section{References}

1. Armarego WLF. Purification of laboratory chemicals. Oxford: Butterworth-Heinemann; 2017.

2. Yoo JH, Roh SG, Lee NH, et al. A case report of a chemical burn due to the misuse of glacial acetic acid. J Plast Reconstr Aesthet Surg 2010;63:e829-31.

3. Coban YK. Superficial burns secondary to misuse of acetic acid solution. J Burn Care Res 2007;28:359-60.

4. Safe Work Australia. Hazardous Chemical Information System (HCIS) [Internet]. Canberra: Safe Work Australia; c2021 [cited 2021 Aug 13]. Available from: http://hcis.safeworkaustralia.gov.au/.

5. Desai B, Desai A. Primary care for emergency physicians. Berlin: Springer; 2016.

6. Fokom-Domgue J, Combescure C, Fokom-Defo V, et al. Performance of alternative strategies for primary cervical cancer screening in sub-Saharan Africa: systematic review and meta-analysis of diagnostic test accuracy studies. BMJ 2015;351:h3084.

7. Tan T, Wong DS. Chemical burns revisited: what is the most appropriate method of decontamination? Burns 2015;41:761-3.

8. Palao R, Monge I, Ruiz M, et al. Chemical burns: pathophysiology and treatment. Burns 2010;36:295-304.

9. Jelenko C III. Chemicals that "burn". J Trauma Acute Care Surg 1974;14:65-72.

10. Oh SK, Lee JW, Jang YC, et al. Analysistic study of chemical burn. J Korean Burn Soc 2002;5:142-7.

11. Seo HH, Kim MK, Lee JW, et al. Case report of glacial acetic acid burns. J Korean Burn Soc 1999;2:47-52. 